\title{
UNBS5162 inhibits SKOV3 ovarian cancer cell proliferation by regulating the PI3K/AKT signalling pathway
}

\author{
QIANG WANG ${ }^{1}$ and WEI SHI ${ }^{2}$ \\ ${ }^{1}$ Department of Gynecology and Obstetrics, The Second Hospital of Jilin University, Changchun, Jilin, Shandong 130000; \\ ${ }^{2}$ Department of Gynecology and Obstetrics, Jinan Central Hospital Affiliated to Shandong University, \\ Jinan, Shandong 250013, P.R. China
}

Received April 27, 2018; Accepted December 6, 2018

DOI: $10.3892 / 01.2019 .9890$

\begin{abstract}
Ovarian cancer is the gynaecological malignancy with the highest mortality rate worldwide, and effective and safe therapeutic methods are limited. UNBS5162, a derivative of naphthalimide, has a clear inhibitory effect on the proliferation of various tumour cells in vitro and in vivo as a pan-antagonist of CXC chemokine ligand expression, but whether it serves a function in ovarian cancer remains unclear. The aim of the present study was to determine the effects of UNBS5162 on the proliferation, migration and invasion of ovarian cancer cells. The cell viability was detected using a Cell Counting Kit-8 (CCK-8) assay. The invasion and migration of SKOV3 cells were determined using Transwell assays. Cell apoptosis was determined using flow cytometry. The apoptosis-associated proteins and associated factors, such as phosphoinositide 3-kinase (PI3K)/protein kinase B (AKT) signalling pathway members, were detected using western blot analysis. The CCK-8 assay revealed that SKOV3 cell viability was affected by UNBS5162 in a dose- and time-dependent manner. In Transwell assays, UNBS5162 inhibited cell invasion and migration. Furthermore, it was identified that UNBS5162 markedly increased the apoptosis rate of SKOV3 cells. Simultaneously, the expression of the anti-apoptotic protein B-cell lymphoma 2 (Bcl-2) was decreased and the expression of the pro-apoptotic proteins active caspase-3 and Bcl-2-associated $\mathrm{X}$ protein were increased in SKOV3 cells treated with UNBS5162. In addition, the expression levels of phospho (p-)AKT/total AKT, p-mammalian
\end{abstract}

Correspondence to: Dr Wei Shi, Department of Gynecology and Obstetrics, Jinan Central Hospital Affiliated to Shandong University, 105 Jiefang Road, Jinan, Shandong 250013, P.R. China

E-mail: shiwei5316289@163.com

Abbreviations: CCK-8, Cell Counting Kit-8; PI3K, phosphoinositide 3-kinase; DMEM, Dulbecco's modified Eagle's medium

Key words: UNBS5162, ovarian cancer, SKOV3 cell line, proliferation, invasion, migration, apoptosis target of rapamycin (mTOR)/total mTOR, p-p70 S6 kinase (p70S6K)/total p70S6K and cyclin D1 were decreased in the UNBS5162-treated group. The results of the present study indicated that UNBS5162 inhibits proliferation, migration and invasion, and induces apoptosis in ovarian cancer cells, which may be regulated by the PI3K/AKT signalling pathway. These results suggest that UNBS5162 may be a potential novel drug for clinical ovarian cancer treatment.

\section{Introduction}

Ovarian cancer is the gynaecological malignancy with the highest mortality rate, with $>120,000$ mortalities worldwide annually $(1,2)$. The 5-year survival rate for ovarian cancer is only $30-40 \%$ (3). Approximately $70 \%$ of patients with ovarian cancer are diagnosed in the later stages of the disease (4). Chemotherapy is a commonly used method for the treatment of ovarian cancer; however, patients with ovarian cancer are likely to develop resistance to chemotherapy drugs owing to continuous use (5). Therefore, development of low toxicity and efficient novel drugs for the treatment of ovarian cancer is urgently required.

Naphthalimide has been a focus of research in the development of antitumour drugs (6,7). Naphthalimides, a class of compounds that bind to DNA by intercalation, exhibit relatively marked anticancer activity against various human cancer cell lines $(7,8)$. Since it has toxic side effects, the primary amine group of naphthalimide has been optimized, and one of the derivatives is UNBS3157 (9). UNBS3157 was designed to avoid the blood toxicity of the clinical metabolism amonafide (10). UNBS3157 is rapidly hydrolysed in physiological saline to produce UNBS5162 which exhibits anticancer activity (11). UNBS5162, a novel type of naphthalimide, was used to avoid the specific effects of the metabolite amonafide, including haemotoxicity (12). UNBS5162 significantly attenuates cell cycle progression of human cancer cells by significantly prolonging the duration of $\mathrm{G}_{2}$ phase (13). UNBS5162 has been identified to decrease levels of CXC chemokine ligand (CXCL) chemokines, including CXCL1, CXCL5 and CXCL8, in experimental prostate cancer and has a good inhibitory effect on the proliferation of tumour cells in vitro and in vivo (14). In summary, UNBS5162 has anticancer effects, and can decrease certain side effects. He et al (12) identified that UNBS5162 
inhibits the proliferation of oesophageal cancer squamous cells through the phosphoinositide 3-kinase (PI3K)/protein kinase B (AKT) signalling pathway. Liu et al (11) identified that UNBS5162 inhibits the proliferation of human lung cancer cells by promoting cell apoptosis. It has also been identified that UNBS5162 has a therapeutic effect in the treatment of human retinoblastoma (13). However, to the best of our knowledge, UNBS5162 has not been used in the treatment of ovarian cancer.

In the present study, we investigated the effect of UNBS5162 treatment on the proliferation, migration and invasion of ovarian cancer SKOV3 cells, which may be regulated by the enhancement of apoptosis and inhibition of PI3K/AKT.

\section{Materials and methods}

Cell lines and cell culture. The ovarian cancer cell line SKOV3 was obtained from the American Type Culture Collection (Manassas, VA, USA). Cells were cultured in Dulbecco's modified Eagle's medium (DMEM; HyClone; GE Healthcare Life Sciences, Logan, UT, USA) supplemented with $10 \%$ fetal bovine serum (FBS; Gibco; Thermo Fisher Scientific, Inc., Waltham, MA, USA), $100 \mathrm{U} / \mathrm{ml}$ penicillin (Sigma-Aldrich; Merck KGaA, Darmstadt, Germany) and $0.1 \mathrm{mg} / \mathrm{ml}$ streptomycin (Sigma-Aldrich; Merck KGaA) at $37^{\circ} \mathrm{C}$ in an incubator containing $5 \% \mathrm{CO}_{2}$. When the cells entered the exponential growth phase, they were washed three times with PBS and digested with trypsin (Beijing Solarbio Science \& Technology, Co., Ltd., Beijing, China). Following rounding of the cells, DMEM was added to end the digestion, and the cells were treated with DMEM containing $10 \%$ FBS repeatedly to obtain a single cell suspension and, finally, the cells were maintained in 6-well plates prior to use in subsequent experiments. A total of $0.1 \%$ dimethylsulfoxide (DMSO) was the negative control (NC) group.

Cell Counting Kit-8 (CCK-8) viability assay. SKOV3 cells were digested in $0.25 \%$ trypsin solution at room temperature for $2 \mathrm{~min}$ and counted to prepare a cell suspension. Subsequently, 96-well plates were seeded at 1,000 cells/well with $100 \mu \mathrm{l}$ cell suspension, whereas $0.2,2,20$ or $200 \mu \mathrm{M}$ UNBS5162 was added to the experimental groups. The cells were cultured in a $\mathrm{CO}_{2}$ incubator as aforementioned, and cell viability was determined every $24 \mathrm{~h}$ using the CCK- 8 assay (Beijing Solarbio Science \& Technology, Co., Ltd.). To each well, $10 \mu \mathrm{l} \mathrm{CCK}-8$ reagent was added and cells were incubated at $37^{\circ} \mathrm{C}$ for $1.5 \mathrm{~h}$. The optical density (OD) values were determined using a microplate reader at $450 \mathrm{~nm}$. Each assay was performed in triplicate.

Cell invasion and migration assays. Matrigel (BD Biosciences, San Jose, CA, USA) was dissolved overnight in serum-free DMEM (diluted 1:6), and 100 $\mu 1$ was added to the upper chamber of 24-well Transwell plates (EMD Millipore, Billerica, MA, USA). Following shaking evenly, the Matrigel was placed in a $\mathrm{CO}_{2}$ incubator for $4-6 \mathrm{~h}$ at $37^{\circ} \mathrm{C}$ until gel formation. The culture medium was dried, and $500 \mu 1$ serum-free medium was added to the bottom of wells to hydrate the basement membrane for $30 \mathrm{~min}$. The cell suspensions, treated with $20 \mu \mathrm{M}$ UNBS5162 for $24 \mathrm{~h}$, were prepared using serum-free DMEM. A $100 \mu \mathrm{l}$ volume of the cell suspension $\left(1 \times 10^{5}\right.$ cells) was loaded into the upper chamber of the Transwell, and $500 \mu 1$ DMEM containing $10 \%$ FBS was added to the bottom of Transwell for incubation overnight. The next day, the Transwell was removed, and cells remaining on the upper chamber were removed with a cotton swab. Following washing with PBS, the cells adhering to the membrane were fixed in $4 \%$ paraformaldehyde for $30 \mathrm{~min}$ at room temperature. Cells were stained with $0.1 \%$ crystal violet for $20 \mathrm{~min}$ at room temperature. Following washing with PBS, five fields of view were selected randomly under an light and inverted microscope, and images were captured for enumeration of the cells. For the migration assay, the experimental procedure was similar, except that Matrigel was not added to the Transwell chamber, and 5,000 cells were used. Each assay was performed three times independently.

Cell apoptosis assay. Following treatment of SKOV3 cells with $20 \mu \mathrm{M}$ UNBS5162 for $24 \mathrm{~h}$, cells were harvested, digested with trypsin without EDTA, centrifuged at $200 \mathrm{x} g$ for $5 \mathrm{~min}$ at room temperature and resuspended in pre-cooled PBS at $4^{\circ} \mathrm{C}$. The cells were centrifuged once again as mentioned above, and the supernatant was carefully aspirated. Subsequently, $1 \mathrm{X}$ binding buffer (Biomiga Inc., San Diego, CA, USA) was added to resuspend the cells, and cells were used at a density of $1-5 \times 10^{6}$ cells $/ \mathrm{ml}$. A $100-\mu 1$ aliquot of the cell suspension was transferred into a $5 \mathrm{ml}$ flow tube, stained with $5 \mu \mathrm{l}$ annexin V/fluorescein isothiocyanate (FITC) (Beijing 4A Biotech Co., Ltd., Beijing, China) for $5 \mathrm{~min}$ at room temperature and kept in a dark place. The samples were stained with $10 \mu \mathrm{l}$ propidium iodide (PI) and $400 \mu \mathrm{l}$ PBS, and cells were collected and detected using a flow cytometry. The results were analysed by FlowJo software (version 7.6.3; FlowJo, LLC, Ashland, OR, USA). The assay was performed in triplicate.

Western blot assay. Following treatment of SKOV3 cells with $0.1 \%$ DMSO and $20 \mu \mathrm{M}$ UNBS5162 for $24 \mathrm{~h}$, proteins were extracted with radioimmunoprecipitation lysis buffer (including protease inhibitor) (Beijing ComWin Biotech Co., Ltd., Beijing, China). Protein concentration was determined using the bicinchoninic acid (Beijing ComWin Biotech Co., Ltd., Beijing, China) method. Proteins were heated at $95^{\circ} \mathrm{C}$ for $5 \mathrm{~min}$, and $\sim 20 \mu \mathrm{g}$ protein/group was added to each well in a vertical electrophoresis tank for SDS-PAGE (10\% gel) prior to transfer onto a polyvinylidene difluoride membrane. Following blocking with 5\% non-fat milk in Tris-buffered saline containing 0.1\% Tween-20 (TBST; Beijing ComWin Biotech Co., Ltd., Beijing, China) at room temperature for $1 \mathrm{~h}$, the membrane was incubated with primary antibodies at $4^{\circ} \mathrm{C}$ overnight. Primary antibodies were against the following: Rabbit anti-human antibodies against AKT (dilution, 1:1,000; cat. no. 4691; Cell Signalling Technology, Inc., Danvers, MA, USA), phospho (p)-AKT (dilution, 1:1,000; cat. no. 4060; Cell Signalling Technology, Inc.), mammalian target of rapamycin (mTOR; dilution, 1:1,000; cat. no. 2983; Cell Signalling Technology, Inc.), p-mTOR (dilution, 1:1,000; cat. no. 5536; Cell Signalling Technology, Inc.), p70 S6 kinase (p70S6K; dilution, 1:1,000; cat. no. 14485-1-AP; ProteinTech Group, Inc., Chicago, IL, USA), p-p70S6K (dilution, 1:1,000; cat. no. 9204; Cell Signalling Technology, Inc.), cyclin D1 (dilution, 1:1,000; cat. no. 60186-1-Ig; ProteinTech Group, 
Inc.), B-cell lymphoma 2 (Bcl-2; dilution, 1:1,000; cat. no. 12789-1-AP; ProteinTech Group, Inc.), Bcl-2-associted X protein (Bax; dilution, 1:1,000; cat. no. 23931-1-AP; ProteinTech Group, Inc.), pro-caspase-3 (dilution, 1:1,000; cat. no. 12742; Cell Signalling Technology, Inc.), active caspase-3 (dilution, 1:1,000; cat. no. 25546-1-AP; ProteinTech Group, Inc.) and $\alpha$-tubulin (dilution, 1:5,000; cat. no. 11224-1-AP; ProteinTech Group, Inc.). Following incubation, the membrane was washed three times in Tris-buffered saline containing $0.1 \%$ Tween- 20 for 5 min each, and then incubated with horseradish peroxidase-labelled goat anti-rabbit antibody (dilution, 1:5,000; cat. no. SA00001-2; ProteinTech Group, Inc.) secondary antibodies at room temperature for $1 \mathrm{~h}$. Following washing, an enhanced chemiluminescence (ProteinTech Group, Inc.) chromogenic substrate was added to visualize the bands. The grey value was determined using Quantity One software (version 4.62; Bio-Rad Laboratories, Inc., Hercules, CA, USA). The expression of each protein was calculated relative to tubulin. Each blot was performed three times.

Statistical analysis. Results were analysed using Student's t-test or analysis of variance with Fisher's least significant difference post hoc test with SPSS statistical analysis software (version 18.0; SPSS, Inc., Chicago, IL, USA). Results are expressed as the mean \pm standard deviation. $\mathrm{P}<0.05$ was considered to indicate a statistically significant difference.

\section{Results}

UNBS5162 inhibits SKOV3 ovarian cancer cell proliferation. A CCK-8 assay was used to determine the effect of UNBS5162 on SKOV3 ovarian cancer cell viability. The viability of SKOV 3 cells significantly decreased following 20 and $200 \mu \mathrm{M}$ UNBS5162 treatment in a dose-dependent manner $(\mathrm{P}<0.01$ vs. NC; Fig. 1A). Therefore, in subsequent experiments, $20 \mu \mathrm{M}$ UNBS5162 was used, as it had a significant and similar inhibitory effect compared with $200 \mu \mathrm{M}$ UNBS5162 and lower general toxicity. UNBS5162 decreased the number of SKOV 3 cells in a time-dependent manner, with a significantly decreased viability compared with the $\mathrm{NC}$ at $72 \mathrm{~h}(\mathrm{P}<0.05$; Fig. 1B). These results suggested that UNBS5162 could effectively inhibit the viability of the ovarian cancer cell line SKOV3.

UNBS5162 inhibits SKOV3 ovarian cancer cell invasion and migration. The effects of UNBS5162 on the invasion and migration of the ovarian cancer cell line SKOV3 were investigated using Transwell assays. The number of crystal violet-stained cells in the invasion and migration assays was decreased by UNBS5162 (Fig. 2A). These results were revealed to be significant $(\mathrm{P}<0.05$; Fig. $2 \mathrm{~B}$ and $\mathrm{C})$, suggesting that UNBS5162 inhibits migration and invasion of ovarian cancer cells.

UNBS5162 promotes SKOV3 cell apoptosis. The effect of UNBS5162 on SKOV3 cell apoptosis was determined using an annexin V/FITC and PI double-staining assay. The apoptosis rate in the UNBS5162-treated group was significantly higher compared with the NC group (24.46\% vs. 5.75\%;
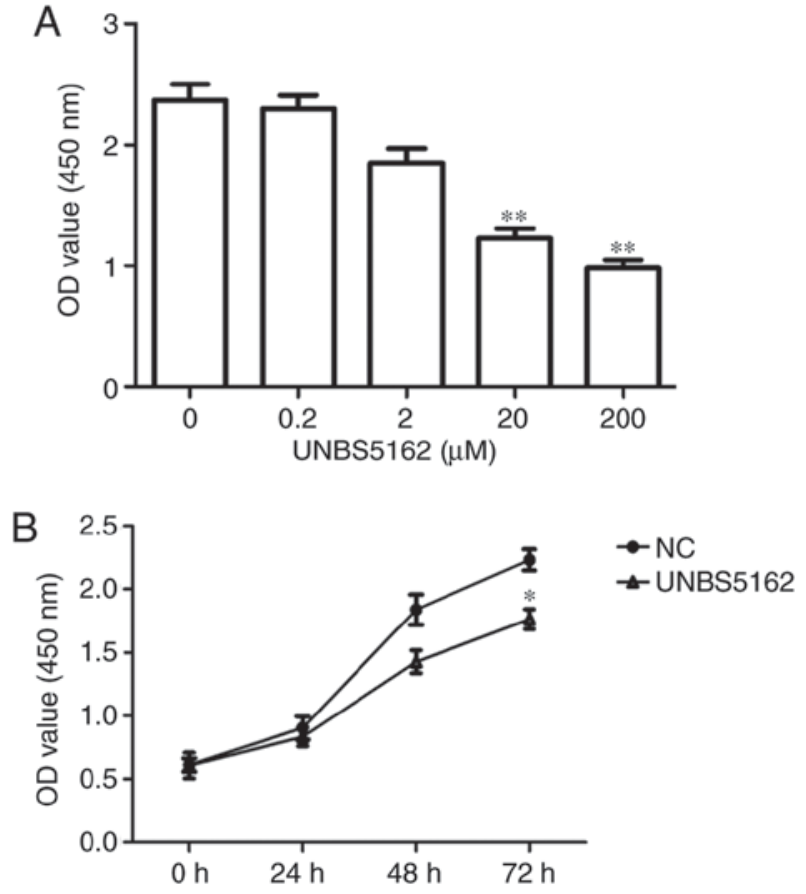

Figure 1. Effect of UNBS5162 on SKOV3 cell proliferation determined using a Cell Counting Kit-8 assay. (A) SKOV3 cells were treated with UNBS5162 $(0,0.2,2,20$ or $200 \mu \mathrm{M})$ for $72 \mathrm{~h}$. (B) UNBS5162 inhibited SKOV3 cell proliferation in a time-dependent manner. ${ }^{*} \mathrm{P}<0.05,{ }^{* *} \mathrm{P}<0.01$ vs. the NC group. NC, negative control; OD, optical density.

$\mathrm{P}<0.05$; Fig. 3A). Furthermore, apoptosis regulators, such as the anti-apoptotic protein $\mathrm{Bcl}-2$, the pro-apoptotic protein active caspase- 3 and Bax, were analysed by western blotting (Fig. 3B). Consistent with the flow cytometric results, the expression of the anti-apoptotic protein Bcl-2 decreased, and the expression of the pro-apoptotic protein active caspase-3 and Bax increased in the UNBS5162-treated group compared with the NC group ( $\mathrm{P}<0.05$, Fig. 3D). These results indicated that UNBS5162 promotes SKOV3 cell apoptosis.

UNBS5162 suppresses the PI3K/AKT pathway in SKOV3 ovarian cancer cells. The PI3K/AKT signalling pathway is an important signalling pathway in tumours. The mTOR, p70S6K and cyclin D1 proteins were selected as indicators to determine the activity of the PI3K/AKT signalling pathway following UNBS5162 treatment. The western blot results indicated that the p-AKT/total AKT and p-mTOR/total mTOR expression ratios were decreased significantly in UNBS5162-treated SKOV3 cells compared with the NC ( $\mathrm{P}<0.05$; Fig. 4). Similarly, the p-p70S6K/total p70S6K expression ratio and cyclin D1 expression level decreased following UNBS5162 treatment $(\mathrm{P}<0.05$; Fig. 4). These results suggested that the proliferation of UNBS5162-treated SKOV3 cells is suppressed via the PI3K/AKT signalling pathway.

\section{Discussion}

In the present study, UNBS5162, a derivative of naphthalimide, was investigated to determine its antitumour effect and the underlying molecular mechanism. Specifically, it was identified that UNBS5162 inhibited SKOV3 cell proliferation, 
A
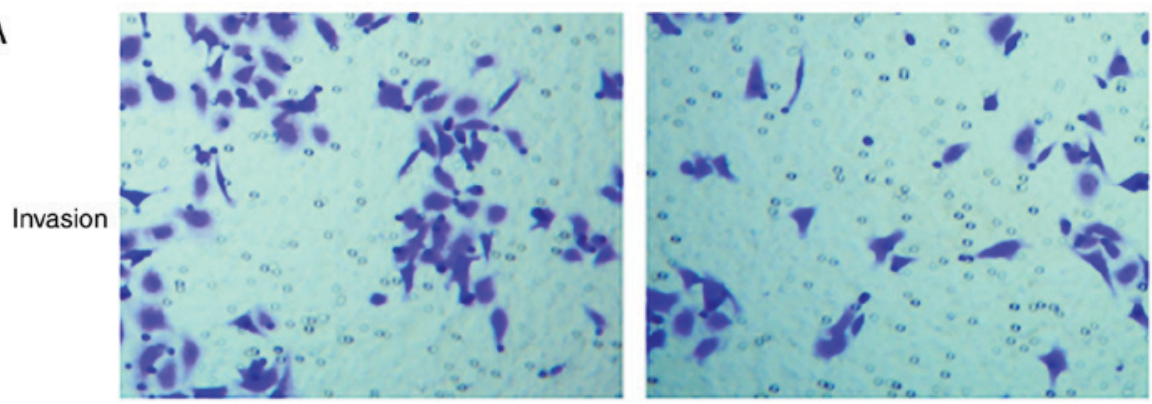

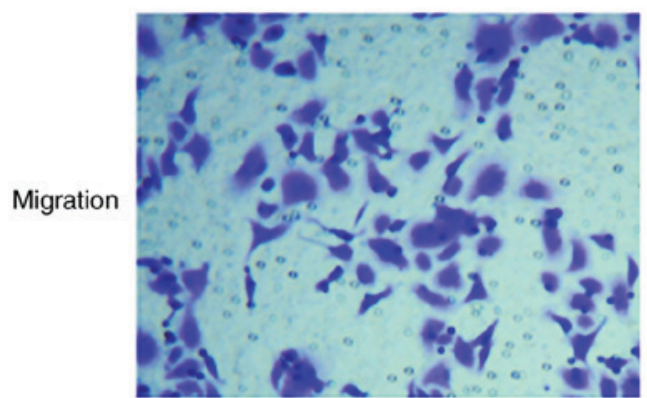

NC

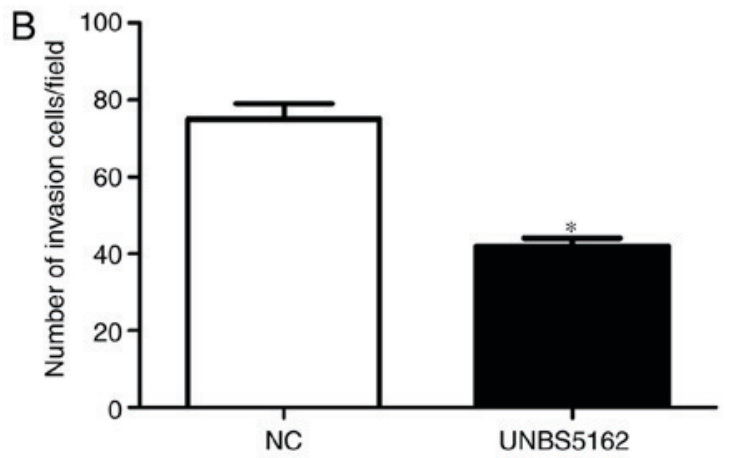

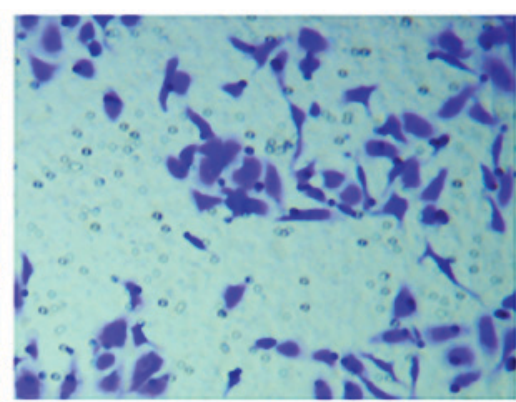

UNBS5162

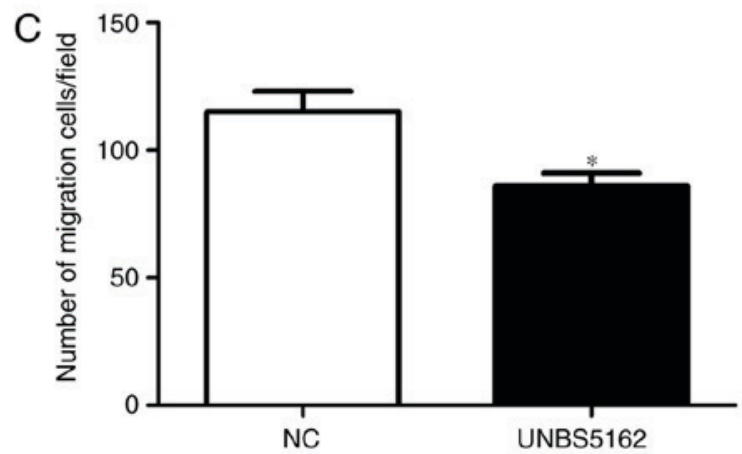

Figure 2. UNBS5162 inhibits SKOV3 cell invasion and migration. (A) Crystal violet-stained invasive and migratory SKOV3 cells were captured using an inverted microscope at x100 magnification. Quantification of (B) invasive and (C) migratory cells. "P $<0.05$ vs. the NC group. NC, negative control.

invasion and migration. Furthermore, it was identified that cell apoptosis was promoted by UNBS5162. Finally, the effects of UNBS5162 on SKOV3 were identified to be associated with the inhibition of the PI3K/AKT signalling pathway.

Owing to the difference in structure of DNA in normal cells and tumour cells, DNA is an ideal target for anticancer drugs (15). DNA intercalators serve an important function in the treatment of tumours. Naphthalimide compounds are DNA intercalators that can insert into the middle of a base pair, causing changes in the topology of the DNA, and thus affecting topoisomerase function and recognition of DNA $(8,16)$. The naphthalimide derivatives, including amonafide (17), mitonafide (18) and UNBS5162 (19), remain in clinical research. However, in clinical trials, mitonafide and amonafide exhibited marked side effects on the central nervous system, leading to thrombocytopenia, anaemia and leukopenia, and thus these two drugs failed to enter Phase III clinical trials (20). In addition, the clinical effects of these two drugs on solid cancers are limited. To decrease further the toxic side effects by removing the primary amine groups, a novel naphthalimide derivative, UNBS3157, was developed which did not exhibit the blood toxicity of amonafide $(9,10)$. In a previous study, UNBS3157 was hydrolysed in physiological saline to produce a novel compound that accounts for its anti-cancer activity, and the product was named UNBS5162 (21). However, limited research has been performed in using UNBS5162 on human ovarian cancer.

The results of the present study indicated that UNBS5162 affects the expression of apoptosis-associated proteins. The results of western blot analysis indicated that the expression of Bcl-2 decreased, and the expression of Bax and active caspase-3 increased in the UNBS5162-treated group. These three proteins are well-characterized regulators of apoptosis (22). Bcl-2 is an anti-apoptotic protein, whereas Bax and active caspase- 3 are pro-apoptotic proteins (23). Apoptosis is an important antitumour mechanism, and a number of antineoplastic agents exert their function in cancer via apoptosis (24). Studies have indicated that oestrogen-induced apoptosis can be used to treat and prevent breast cancer (25). Shukla et al (26) reported a number of applications of apoptosis in prostate cancer. Similarly, UNBS5162 could inhibit A549 non-small cell lung cancer cell proliferation by promoting apoptosis (11). In the present study, it was identified that $20 \mu \mathrm{M}$ UNBS5162 exhibited a marked and similar inhibitory 

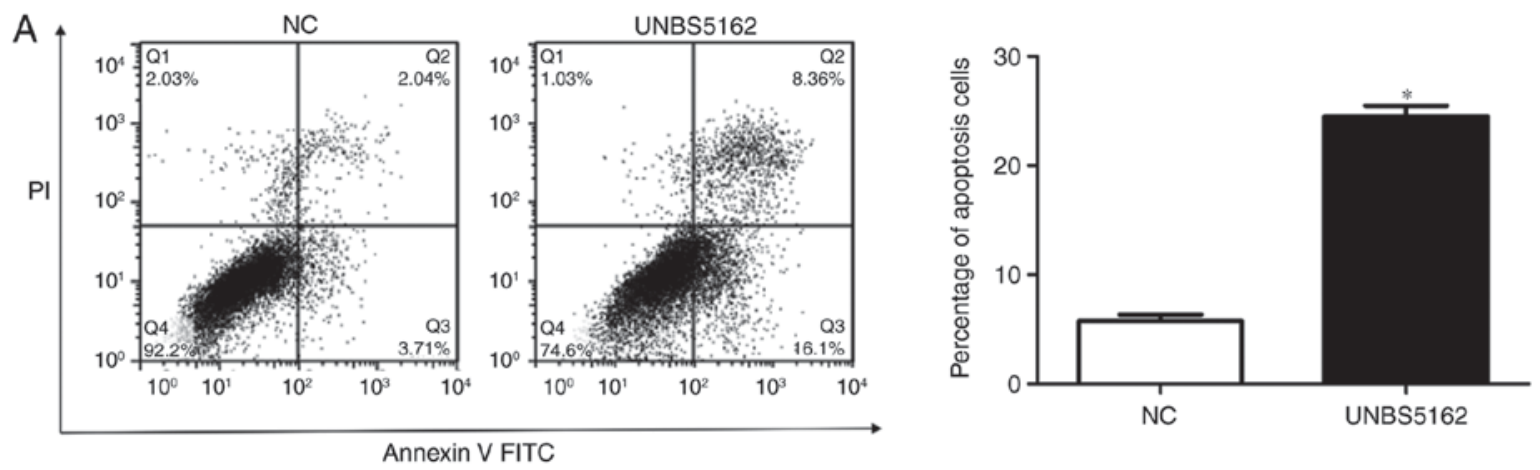

B
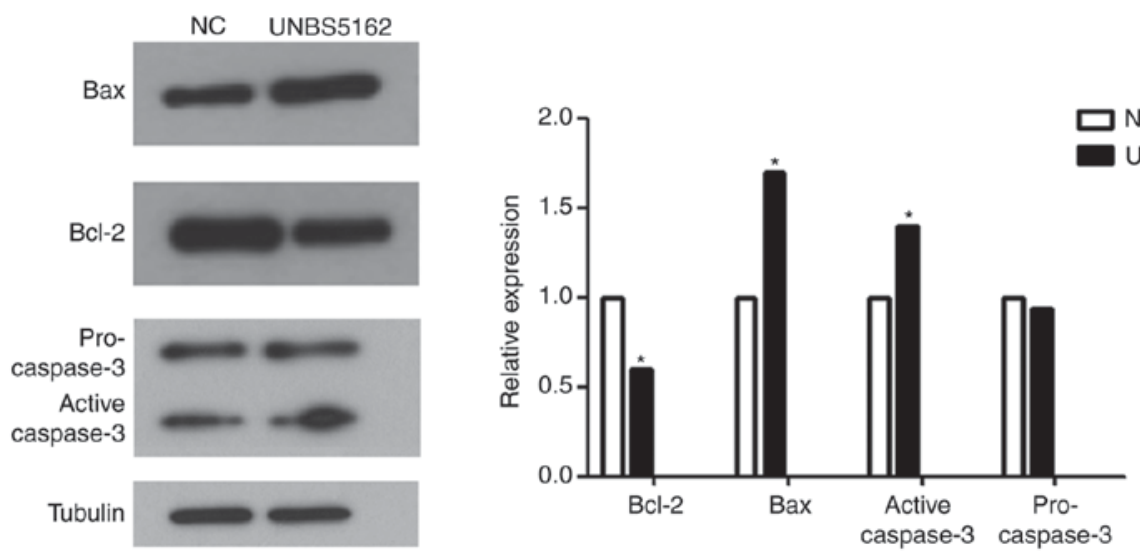

Figure 3. UNBS5162 induces SKOV3 cell apoptosis. (A) SKOV3 cells, treated with UNBS5162 for $24 \mathrm{~h}$, were labelled with annexin V/FITC and PI and analysed by flow cytometry. The proportion of apoptotic cells was determined. (B) Western blot analysis of SKOV3 cells treated with UNBS5162 for $24 \mathrm{~h}$. The band intensities were quantified relative to tubulin expression. " $\mathrm{P}<0.05$ vs. NC group. NC, negative control; PI, propidium iodide; FITC, fluorescein isothiocyanate; Bcl-2, B-cell lymphoma 2; Bax, Bcl-2-associated X protein.
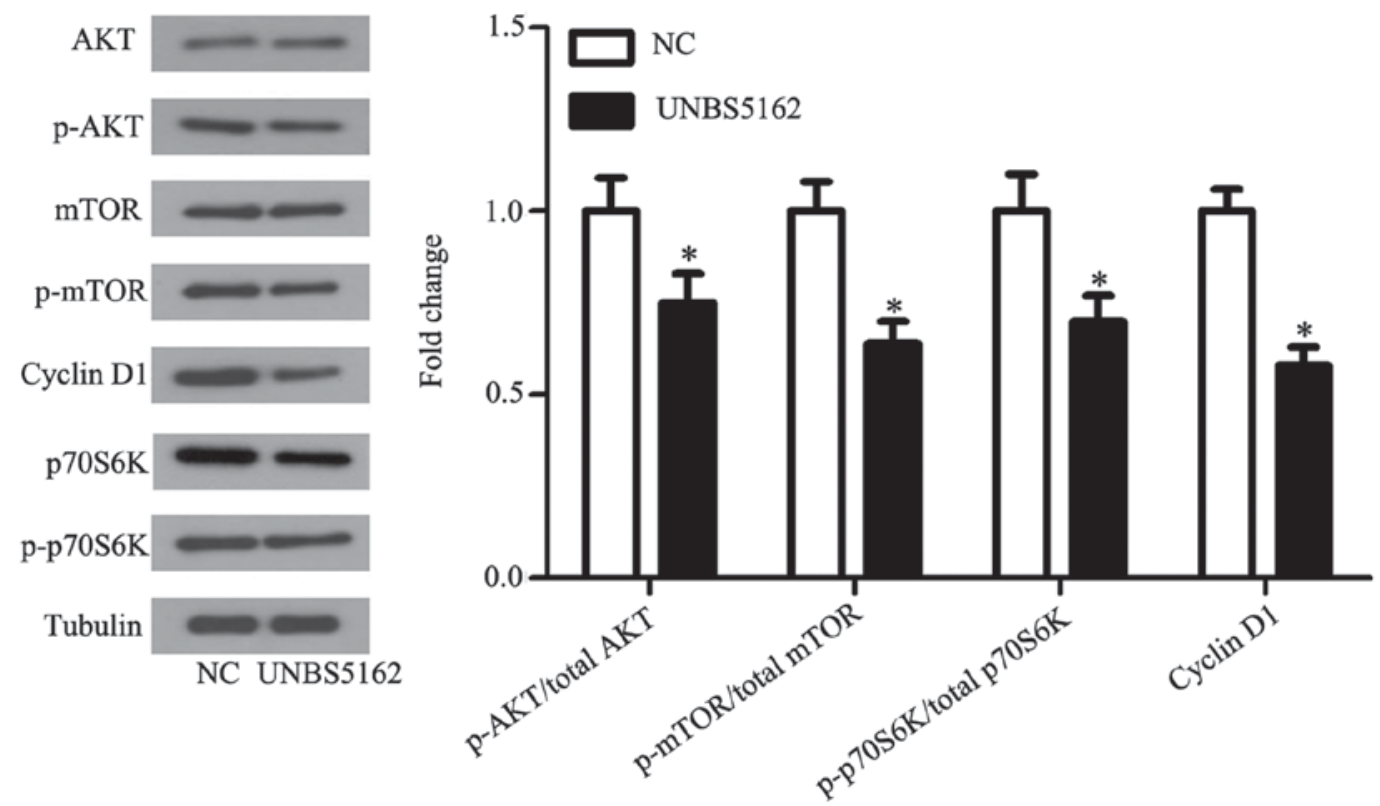

Figure 4. Effects of UNBS5162 on the phosphoinositide 3-kinase/AKT signalling pathway in SKOV3 cells. Expression levels of AKT, p-AKT, mTOR, p-mTOR, p70S6K, p-p70S6K and cyclin D1 were determined in the UNBS5162-treated and untreated SKOV3 cells using western blot analysis. The relative protein levels of p-AKT/total AKT, p-mTOR/total mTOR, p-p70S6K/total p70S6K and cyclin D1 were quantified. "P<0.05 vs. the NC group. AKT, protein kinase B; p-, phospho-; mTOR, mammalian target of rapamycin; p70S6K, p70 S6 kinase; NC, negative control.

effect on, and low toxicity towards, SKOV3 ovarian cancer cells. The activation of apoptosis is regulated by a number of signalling pathways, among which the PI3K/AKT signalling pathway is important (27). PI3K, as a member of the lipid kinase family, serves a major function in the regulation of apoptosis, angiogenesis, cellular metabolism, senescence and 
other processes (28). The PI3K/AKT signalling pathway was identified to be the most frequently affected cancer pathway at the genetic level (29). The PI3K/AKT signalling pathway has a function in ovarian cancer (30). The key protein mTOR, which is a downstream kinase of the PI3K/AKT signalling pathway, has an important function in the proliferation, migration and invasion of cancer cells (31). Previous studies also have indicated that $\mathrm{p} 70 \mathrm{~S} 6 \mathrm{~K}$ and cyclin D1 are located downstream of the PI3K/AKT signalling pathway, which is associated with cell proliferation $(32,33)$. The results of the present study are consistent with those of these previous studies, indicating that UNBS5162 targets key components of the PI3K/AKT signalling pathway, which may be important in the successful treatment of ovarian cancer.

The present study was performed to elucidate the underlying molecular mechanism of the effect of UNBS5162 in ovarian cancer; however, it may have certain limitations. For instance, the use of other cell lines, inhibition such as using short interfering RNA to interfere with the PI3K/AKT signalling pathway and the impact of other signalling pathways are being assessed in our laboratory. The lack of data on non-cancerous cells used as a negative control is also a limitation of the present study. In addition, in vivo experimental verification is required.

In summary, the results of the present study indicate that UNBS5162 could inhibit ovarian cancer cell proliferation, invasion and migration, and promote cell apoptosis, potentially through the PI3K/AKT signalling pathway. The results of the present study suggest the possibility of further clinical applications of UNBS5162 in the treatment of ovarian cancer.

\section{Acknowledgements}

Not applicable.

\section{Funding}

No funding was received.

\section{Availability of data and materials}

The datasets used and/or analysed during the current study are available from the corresponding author on reasonable request.

\section{Authors' contributions}

QW and WS conceived and designed the study, performed the study, analysed and interpreted the data, and wrote the paper.

\section{Ethics approval and consent to participate}

Not applicable.

\section{Patient consent for publication}

Not applicable.

\section{Competing interests}

The authors declare that they have no competing interests.

\section{References}

1. Worzfeld T, Pogge von Strandmann E, Huber M, Adhikary T, Wagner U, Reinartz S and Müller R: The unique molecular and cellular microenvironment of ovarian cancer. Front Oncol 7: 24, 2017.

2. Yan B, Yin F, Wang QI, Zhang W and Li LI: Integration and bioinformatics analysis of DNA-methylated genes associated with drug resistance in ovarian cancer. Oncol Lett 12: 157-166, 2016.

3. Faber MT, Kjaer SK, Dehlendorff C, Chang-Claude J, Andersen KK, Høgdall E, Webb PM, Jordan SJ, Australian Cancer Study (Ovarian Cancer); Australian Ovarian Cancer Study Group, et al: Cigarette smoking and risk of ovarian cancer: A pooled analysis of 21 case-control studies. Cancer Causes Control 24: 989-1004, 2013.

4. Weidle UH, Birzele F, Kollmorgen G and Rueger R: Mechanisms and targets involved in dissemination of ovarian cancer. Cancer Genomics Proteomics 13: 407-423, 2016.

5. Correa RJ, Valdes YR, Peart TM, Fazio EN, Bertrand M, McGee J, Préfontaine M, Sugimoto A, DiMattia GE and Shepherd TG: Combination of AKT inhibition with autophagy blockade effectively reduces ascites-derived ovarian cancer cell viability. Carcinogenesis 35: 1951-1961, 2014.

6. Li S, Xu S, Tang Y, Ding S, Zhang J, Wang S, Zhou G, Zhou C and Li X: Synthesis, anticancer activity and DNA-binding properties of novel 4-pyrazolyl-1,8-naphthalimide derivatives. Bioorg Med Chem Lett 24: 586-590, 2014.

7. Zhao L, Li J, Li Y, Liu J, Wirth T and Li Z: Selenium-containing naphthalimides as anticancer agents: Design, synthesis and bioactivity. Bioorg Med Chem 20: 2558-2563, 2012.

8. Ingrassia L, Lefranc F, Kiss R and Mijatovic T: Naphthalimides and azonafides as promising anti-cancer agents. Curr Med Chem 16: 1192-1213, 2009.

9. Dumont P, Ribaucour F, Quaquebeke EV, Darro F and Kiss R: UNBS3157, a new amonafide derivative with improved in vivo efficacy and decreased toxicity. Cancer Res 66 (Supp): 1105, 2006.

10. Van Quaquebeke E, Mahieu T, Dumont P, Dewelle J, Ribaucour F, Simon G, Sauvage S, Gaussin JF, Tuti J, El Yazidi M, et al: 2,2,2-Trichloro-N-(\{2-[2-(dimethylamino)ethyl]-1,3-dioxo-2,3dihydro-1H-benzo[de] isoquinolin-5-yl\}carbamoyl)acetamide (UNBS3157), a novel nonhematotoxic naphthalimide derivative with potent antitumor activity. J Med Chem 50: 4122-4134, 2007.

11. Liu C, Xing J and Gao Y: UNBS5162 inhibits the proliferation of human A549 non-small-cell lung cancer cells by promoting apoptosis. Thorac Cancer 9: 105-111, 2018.

12. He D and Zhang S: UNBS5162 inhibits the proliferation of esophageal cancer squamous cells via the PI3K/AKT signalling pathway. Mol Med Rep 17: 549-555, 2018.

13. Wang B, Shen J and Wang J: UNBS5162 inhibits proliferation of human retinoblastoma cells by promoting cell apoptosis. Onco Targets Ther 10: 5303-5309, 2017.

14. Mijatovic T, Mahieu T, Bruyere C, De Nève N, Dewelle J, Simon G, Dehoux MJ, van der Aar E, Haibe-Kains B, Bontempi G, et al: UNBS5162, a novel naphthalimide that decreases CXCL chemokine expression in experimental prostate cancers. Neoplasia 10: 573-586, 2008.

15. Agudelo D, Bourassa P, Bérubé G and Tajmir-Riahi HA: Intercalation of antitumor drug doxorubicin and its analogue by DNA duplex: Structural features and biological implications. Int J Biol Macromol 66: 144-150, 2014.

16. Gellerman G: Recent developments in the synthesis and applications of anticancer amonafide derivatives. A mini review. Letters Drug Design Discov 13: 47-63, 2016.

17. Zhao J, Lu M, Lai H, Lu H, Lalevée J, Barner-Kowollik C, Stenzel MH and Xiao P: Delivery of amonafide from fructose-coated nanodiamonds by oxime ligation for treatment of human breast cancer. Biomacromolecules 19: 481-489, 2018.

18. Ge C, Chang L, Zhao Y, Chang C, Xu X, He H, Wang Y, Dai F, Xie $S$ and Wang C: Design, synthesis and evaluation of naphthalimide derivatives as potential anticancer agents for hepatocellular carcinoma. Molecules 22: E342, 2017.

19. Mahieu T, Mijatovic T, Quaquebeke EV, Lefranc F, Vynckt FV, Darro F and Kiss R: UNBS5162 is a novel naphthalimide derivative that induces autophagy and senescence in human prostate cancer cells. Mol Cancer Ther 6: 3373S, 2007.

20. Antonini I, Volpini R, Dal Ben D, Lambertucci C and Cristalli G: Design, synthesis, and biological evaluation of new mitonafide derivatives as potential antitumor drugs. Bioorg Med Chem 16: 8440-8446, 2008. 
21. Mahadevan D, Northfelt DW, Chalasani P, Rensvold D, Kurtin S, Von Hoff DD, Borad MJ and Tibes R: Phase I trial of UNBS5162, a novel naphthalimide in patients with advanced solid tumors or lymphoma. Int J Clin Oncol 18: 934-941, 2013.

22. Mei JM and Niu CS: Effects of CDNF on 6-OHDA-induced apoptosis in $\mathrm{PC} 12$ cells via modulation of $\mathrm{Bcl}-2 / \mathrm{Bax}$ and caspase-3 activation. Neurol Sci 35: 1275-1280, 2014.

23. Zhuang RJ, Ma J, Shi X, Ju F, Ma SP, Wang L, Cheng BF, Ma YW, Wang M, Li T, et al: Cold-inducible protein RBM3 protects UV irradiation-induced apoptosis in neuroblastoma cells by affecting $\mathrm{p} 38$ and JNK pathways and $\mathrm{Bcl} 2$ family proteins. J Mol Neurosci 63: 142-151, 2017.

24. Nakamura Y, Ise K, Yamazaki Y, Fujishima F, McNamara KM and Sasano H: Serotonin receptor 4 (5-hydroxytryptamine receptor Type 4) regulates expression of estrogen receptor beta and cell migration in hormone-naive prostate cancer. Indian J Pathol Microbiol 60: 33-37, 2017.

25. Jordan VC: The new biology of estrogen-induced apoptosis applied to treat and prevent breast cancer. Endocr Relat Cancer 22: R1-R31, 2015.

26. Shukla S, Fu P and Gupta S: Apigenin induces apoptosis by targeting inhibitor of apoptosis proteins and $\mathrm{Ku} 70-\mathrm{Bax}$ interaction in prostate cancer. Apoptosis 19: 883-894, 2014.

27. Zhou ZW, Li XX, He ZX, Pan ST, Yang Y, Zhang X, Chow K Yang T, Qiu JX, Zhou Q, et al: Induction of apoptosis and autophagy via sirtuin1- and PI3K/Akt/mTOR-mediated pathways by plumbagin in human prostate cancer cells. Drug Des Devel Ther 9: 1511-1554, 2015.
28. Akinleye A, Avvaru P, Furqan M, Song Y and Liu D: Phosphatidylinositol 3-kinase (PI3K) inhibitors as cancer therapeutics. J Hematol Oncol 6: 88, 2013.

29. Fang WL, Huang KH, Lan YT, Lin $\mathrm{CH}$, Chang SC, Chen MH, Chao Y, Lin WC, Lo SS, Li AF, et al: Mutations in PI3K/AKT pathway genes and amplifications of PIK3CA are associated with patterns of recurrence in gastric cancers. Oncotarget 7: 6201-6220, 2016

30. Huang J, Zhang L, Greshock J, Colligon TA, Wang Y, Ward R, Katsaros D, Lassus H, Butzow R, Godwin AK, et al: Frequent genetic abnormalities of the PI3K/AKT pathway in primary ovarian cancer predict patient outcome. Genes Chromosomes Cancer 50: 606-618, 2011.

31. Zhang L, Huo X, Liao Y, Yang F, Gao L and Cao L: Zeylenone, a naturally occurring cyclohexene oxide, inhibits proliferation and induces apoptosis in cervical carcinoma cells via PI3K/AKT/mTOR and MAPK/ERK pathways. Sci Rep 7: 1669, 2017.

32. Halacli SO and Dogan AL: FOXP1 regulation via the PI3K/Akt/p70S6K signalling pathway in breast cancer cells. Oncol Lett 9: 1482-1488, 2015.

33. Wang HY, Yang SL, Liang HF and $\mathrm{Li} \mathrm{CH}$ : HBx protein promotes oval cell proliferation by up-regulation of cyclin D1 via activation of the MEK/ERK and PI3K/Akt pathways. Int J Mol Sci 15: 3507-3518, 2014. 